Article

\title{
Evaluation of Soil Properties, Topographic Metrics, Plant Height, and Unmanned Aerial Vehicle Multispectral Imagery Using Machine Learning Methods to Estimate Canopy Nitrogen Weight in Corn
}

\author{
Jody Yu ${ }^{1, *(\mathbb{D})}$, Jinfei Wang ${ }^{1,2}$ and Brigitte Leblon ${ }^{3}$ \\ 1 Department of Geography and Environment, The University of Western Ontario, \\ London, ON N6G 3K7, Canada; jfwang@uwo.ca \\ 2 The Institute for Earth and Space Exploration, The University of Western Ontario, \\ London, ON N6A 3K7, Canada \\ 3 Faculty of Forestry and Environmental Management, University of New Brunswick, \\ Fredericton, NB E3B 5A3, Canada; bleblon@unb.ca \\ * Correspondence: jyu466@uwo.ca
}

\section{check for} updates

Citation: Yu, J.; Wang, J.; Leblon, B Evaluation of Soil Properties, Topographic Metrics, Plant Height, and Unmanned Aerial Vehicle Multispectral Imagery Using Machine Learning Methods to Estimate Canopy Nitrogen Weight in Corn. Remote Sens. 2021, 13, 3105. https://doi.org/10.3390/rs13163105

Academic Editor: Adriaan van Niekerk

Received: 24 June 2021

Accepted: 2 August 2021

Published: 6 August 2021

Publisher's Note: MDPI stays neutral with regard to jurisdictional claims in published maps and institutional affiliations.

Copyright: (c) 2021 by the authors. Licensee MDPI, Basel, Switzerland. This article is an open access article distributed under the terms and conditions of the Creative Commons Attribution (CC BY) license (https:// creativecommons.org/licenses/by/ $4.0 /)$.

\begin{abstract}
Management of nitrogen (N) fertilizers is an important agricultural practice and field of research to minimize environmental impacts and the cost of production. To apply $\mathrm{N}$ fertilizer at the right rate, time, and place depends on the crop type, desired yield, and field conditions. The objective of this study is to use Unmanned Aerial Vehicle (UAV) multispectral imagery, vegetation indices (VI), crop height, field topographic metrics, and soil properties to predict canopy nitrogen weight $\left(\mathrm{g} / \mathrm{m}^{2}\right)$ of a corn field in southwestern Ontario, Canada. Random Forests (RF) and support vector regression (SVR) models were evaluated for canopy nitrogen weight prediction from 29 variables. RF consistently had better performance than SVR, and the top-performing validation model was RF using 15 selected height, spectral, and topographic variables with an $\mathrm{R}^{2}$ of 0.73 and Root Mean Square Error (RMSE) of $2.21 \mathrm{~g} / \mathrm{m}^{2}$. Of the model's 15 variables, crop height was the most important predictor, followed by 10 VIs, three MicaSense band reflectance mosaics (blue, red, and green), and topographic profile curvature. The model information can be used to improve field nitrogen prediction, leading to more effective and efficient $\mathrm{N}$ fertilizer management.
\end{abstract}

Keywords: Unmanned Aerial Vehicle (UAV); precision agriculture; nitrogen management; machine learning; Random Forests; canopy nitrogen weight; maize

\section{Introduction}

Agriculture is an important industry as the basis of food security, and as a significant aspect of the world economy. However, factors such as rapidly increasing global demand, fluctuations in production due to climate change, and a greater awareness of the negative environmental impact of agriculture on surrounding ecosystems, contribute to an increasing need for more efficient and sustainable farming practices. Especially in Canada, where agriculture is a significant industry, developing agricultural methods to be adaptable and resilient is necessary [1]. This is possible through precision agriculture (PA), a management technique that selectively applies crop farming resources such as fertilizer, water, pesticides, and herbicides based on the plant needs within a field [2-4].

One of the main fields of applications of precision agriculture is the management of nitrogen fertilizers [5,6]. Nitrogen is an essential macronutrient to plants, as a major constituent of organic material, enzymic processes, and oxidation-reduction reactions [7]. As such, nitrogen content in above-ground plant tissue is an important indicator of crop health and yield potentials. Several global studies demonstrate that the mean nitrogen recovery 
efficiency by annual crops was less than $50 \%$ of the amount of fertilizer applied $[6,8]$. Nitrogen is one of the most expensive nutrients to supply, and commercial fertilizers represent a major cost in plant production [9]. Rates of nitrogen fertilizer application depend on the crop type, desired yield, nitrogen present in the soil, and subsequently in the plants [7]. Excess nitrogen can reduce crop yield and can be leached from the soil, contaminating surface and groundwater, leading to harmful effects on human health and ecosystem consequences such as algal blooms and hypoxia in water bodies [10]. The United Nations Food and Agriculture Organization identifies classes of agricultural climate adaptation, one major class being management of field operation inputs including fertilizers [11]. As such, optimizing the management of nitrogen fertilizers is an important field of research as new methods and technology are developed to improve nutrient use efficiency, quality, and crop yield while minimizing significantly negative environmental impacts and cost of production.

Literature does include much research on crop canopy nitrogen retrieval using UAVs, but model parameters are often focused on spectroscopy with the use of vegetation indices and spectral remote sensors [12]. PA incorporates the use of many different types of spatial technologies such as geographic information systems (GIS), precision machinery, and remote sensing imagery to ground-based data collection [13]. In PA, remote sensing imagery is especially useful because it does not require physical or destructive contact with plants to gather valuable crop information. The spectral information provided by the imagery can be transformed into vegetation indices (VIs). VIs are mathematical combinations or transformations of spectral bands that have been widely used in agricultural research because they allow for deriving of specific plant properties such as chlorophyll or nutrient content by taking advantage of the differential spectral properties of plants in the visible and near-infrared wavelengths [14-16]. The resulting VI data can then provide timely information for monitoring field conditions and crop health, allowing for the optimal number of resources to be placed where they are needed, when they are needed.

In PA, crop monitoring has largely been conducted using optical satellites [17]. As demand for timely, accurate, and cost-effective data on the earth's surface increased in the last few decades, numerous satellite systems have been launched. Examples of optical satellites in operation include Landsat 8 (since 2013) and Sentinel-2 (since 2015), which have been used in studies on agriculture management [4]. The Landsat program, which began in 1972 with the launch of Landsat 1, is the longest-running program for satellite imagery of the earth [18]. Landsat 8 Operational Land Imager has nine spectral bands including visible, near-infrared, and shortwave infrared, with varying spatial resolutions of 15 to $30 \mathrm{~m}$. Taking more than 700 scenes a day, it has a 16-day revisit time to the same area. Sentinel-2 has 13 spectral bands in the visible, near-infrared, and shortwave infrared with varying spatial resolutions of $10 \mathrm{~m}, 20 \mathrm{~m}$, and $60 \mathrm{~m}$ [19]. With the constellation of twin satellites, the revisit cycle over an area is five days.

Limitations in optical satellite imagery include low spatial sensitivity, as the spatial resolution in the range of meters allows for analysis of larger-scale regional or national areas but is too coarse for small-scale crop fields. The temporal sensitivity can be rather low, as in the case of Landsat 8 ; within a 16-day revisit time, crops would have changed significantly and valuable information on the different stages of growth would not be obtained. In addition to factors such as geometric distortion, atmospheric distortion, and cloud cover obscuring view of the land, advanced processing expertise may be required to ensure sufficient image quality [20]. In comparison, UAV-based remote sensing can provide lower cost and higher spatial and temporal resolution data for crop management. Individuals with basic training can operate a UAV using programmed routes and collect images with $<10 \mathrm{~cm}$ resolutions [21]. They can be flown to capture more frequent image data, including monitoring each significant stage of crop growth and offer flexibility in operation for times when weather is most suitable. This makes them ideal for field management conducted in a timely and accurate manner according to the needs of the crop [22]. Compared to satellites, overall UAV-based systems are often lower in cost for data collection and processing. As 
such, the use of UAV imagery in PA has become a research area of great interest due to its potential for larger environmental and economic impacts [4].

Corn was selected for this study because it is among the most grown crops in Ontario [17]. Recent studies have tested the use of linear regression, Random Forest (RF), and Support Vector Regression (SVR) models in UAV-based canopy nitrogen weight prediction models [23]. Although linear regression is a commonly used method to predict nitrogen, some VIs (e.g., NDVI) may saturate beyond the early growth crop stages and models may have reduced accuracy due to multicollinearity [24]. By contrast, machine learning-based regression methods such as RF and SVR have been found to produce more accurate models compared to classical linear regression methods, as they are unaffected by the assumptions of linear regression [24]. However, Lee et al. (2020) considered only UAV spectral information and canopy nitrogen weight prediction in their study. The nitrogen prediction may be improved if plant physiology, topographic metrics, and soil variables are included in the analysis, given that crop nitrogen highly depends on these variables [7].

To make well-informed fertilization management decisions, knowledge about the plant nutrient supply, health, and several environmental factors such as water availability, soil quality, and micro-topography of a field are key. The objectives of this study include, (i) studying the relationship between the spatial variation of canopy nitrogen weight and factors such as plant height, topographic metrics, soil chemical properties, and soil moisture conditions within a corn field in Southwestern Ontario using multispectral UAV-based imagery; (ii) determining the optimal combination(s) of spectral variable(s), crop plant physiology variables, and/or environmental conditions (soil, water, topographic data) for corn canopy nitrogen estimation and prediction; and (iii) evaluating the temporal variation of nitrogen estimation and prediction during early growth stages of corn using UAV images and select variables.

\section{Materials and Methods}

\subsection{Study Area and Data Collection}

The study site is in Central Elgin, Ontario, Canada (Figure 1). Fieldwork was conducted during June-July 2020 with an average temperature of $25^{\circ} \mathrm{C}$ and high humidity averaging $71 \%$, typical of southwestern Ontario's humid continental climate zone. The study area is situated in a predominantly agricultural area, about $25 \mathrm{~km}$ south of London, Ontario's urban center. The corn was planted in early April, began sprouting in early June, and was harvested in late October once the plants were fully dried.

Data was collected from a corn field about 75 ha large, sown with cultivars "DKC4856RI". Beginning in early June, a total of five sampling dates were collected with at least seven days between each visit as the crop reached different significant growth stages. Corn growth stages were recorded following the Biologische Bundesanstalt, Bundessortenamt und $\mathrm{CHemische}(\mathrm{BBCH})$ scale [25]. We acquired and used data during the corn crops' early growth periods (BBCH 0-49) in June for nitrogen estimation, which is especially important because fertilizers used during this time can have the greatest impact on the final quantity and quality of yield [7,26]. During July to August, corn crops reached middle to late growth stages (BBCH 50+) and application of nitrogen fertilizer is not recommended after plants begin tasselling [6]. The plant slows root nitrogen uptake, beginning to translocate nitrogen from vegetation to the grains, and excess fertilizer can leach from the field [27]. Corn plants reached full maturity in early September, and the crop was left to dry in the field before harvest in October. 


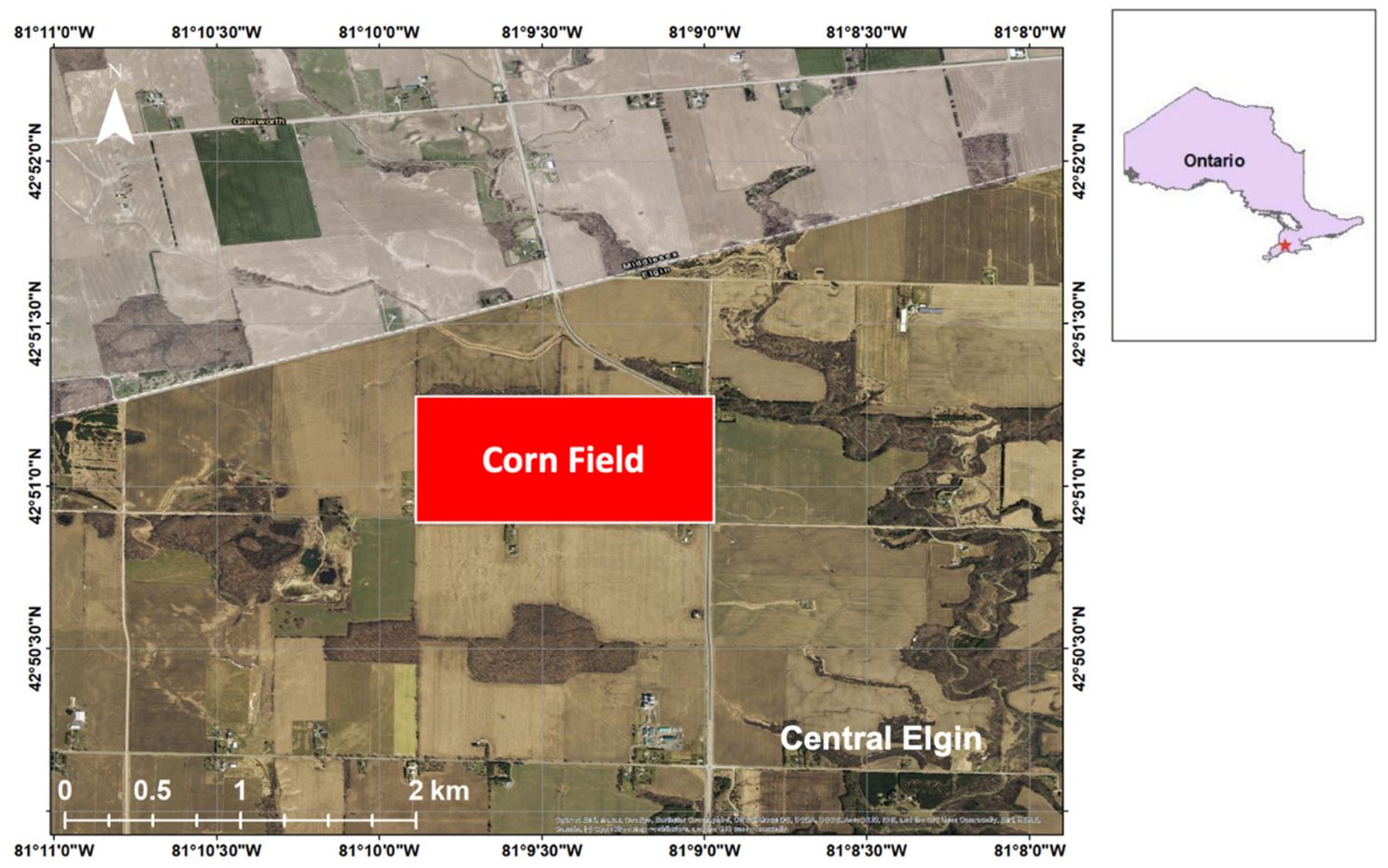

Figure 1. Location of the corn field in Central Elgin, Ontario, Canada, over a Google Earth image.

Before selecting sample points, a DJI Phantom 4 Real-Time Kinematics (RTK) UAV was flown over the bare soil of the field. With the UAV connected to an RTK global navigation satellite system (GNSS) base station, images have precise positioning metadata with $1 \mathrm{~cm}$ horizontal positioning accuracy and $1.5 \mathrm{~cm}$ vertical positioning accuracy. These images were used to create a bare earth digital elevation model (DEM). Using Google Earth, 40 sample points were selected in the field based on the DEM and the UAV imagery (Figure 2). The sample points had to cover the variation of field topography sloping down from west to east. Considering corn row directions heading north-south, navigating along rows was more efficient compared to against rows. As well, the following factors were considered for sample point placement: The large dimensions of the field $(1.2 \mathrm{~km} \times 0.7 \mathrm{~km})$, the intensive labour required, and the time-sensitive nature of in-situ data collection and processing. The sample points were placed in groups of ten spaced $60 \mathrm{~m}$ from one another, with a distance between groups at least $200 \mathrm{~m}$ apart to include a representative sample distribution of the field. A minimum distance of $50 \mathrm{~m}$ from roads was to reduce possible effects of transportation pollution. The sample points were exported from Google Earth to a KML file and downloaded onto mobile devices. During the first fieldwork date using the KML file for navigation, red flags were placed at the sample points for accurate positioning in the following weeks.

At each sampling point, fresh biomass samples were destructively collected by cutting the corn plant at the stem base above ground. The number of plants within a $1 \mathrm{~m}^{2}$ block around the sample point were counted, and two plants were collected and placed in plastic bags. The average distance between rows was $80 \mathrm{~cm}$. Following fieldwork collection on the same day, the fresh biomass was weighed in grams then fully dried in an oven at $60^{\circ} \mathrm{C}$ for $48-72 \mathrm{~h}$. Dry biomass was weighed and leaves at the top of the plant constituting the canopy layer were separated for A\&L Canada Laboratories plant analysis using the Laboratory Equipment Company (LECO) FP628 nitrogen determinate combustion method [28]. The process involves grinding biomass leaves into a fine powder, which can be passed through a $1 \mathrm{~mm}$ sieve, and the combustion method obtains the leaf nitrogen content percentage. 




Figure 2. Digital elevation model demonstrating the variation of the corn field's topography and the distribution of sample points.

On every fieldwork date, at each sampling point within a $1 \mathrm{~m}^{2}$ block, six measurements of plant height in centimeters were taken to calculate an average height. Detailed plant phenology was recorded to determine growth stages according to the Biologische Bundesanstalt, Bundessortenamt und $\mathrm{CHemische}(\mathrm{BBCH})$ scale at each sample point, as there can be variation in the field depending on growing conditions [28]. Six measurements of soil moisture were collected using an ML3 ThetaProbe (Delta-T Devices Ltd., England) [29] and averaged. On the first fieldwork date of 8 June, soil samples in the 0-30 cm surface layer were collected and sent to A\&L Canada Laboratories for Vittellus soil health analysis [30]. The test results include values of soil nitrate-nitrogen, mineralizable nitrogen, water extracted soil nitrate, water extracted total nitrogen, soil textural class, and A\&L's Soil Health Index rating.

\subsection{UAV Imagery}

For this study, two types of UAVs were used: a Da-Jiang Innovations (DJI) (DJI, China) Matrice 100 and a DJI Phantom 4 Real-Time Kinematics (RTK) (Figure 3). The DJI Phantom 4 RTK was released in 2018, designed for centimeter-accurate horizontal and vertical positioning in images using a complementary metal-oxide-semiconductor (CMOS) sensor [31]. Connected to an RTK global navigation satellite system (GNSS) base station, images with precise positioning metadata can be used to generate $3 \mathrm{D}$ point cloud datasets and digital elevation models (DEM). For this study, the DJI Phantom 4 RTK was flown at $30 \mathrm{~m}$ altitude as per manufacturer recommendations for optimal performance of the UAV's visual sensor system and RTK base station connection. The image resolution was $0.8 \times 0.8 \mathrm{~cm}$, and capture was set to $80 \%$ side and $80 \%$ front image overlap. Studies indicate that fine resolution $(<10 \mathrm{~cm})$ and high image overlap have higher success for mosaicking images together when crop canopy densifies through the season [21]. 

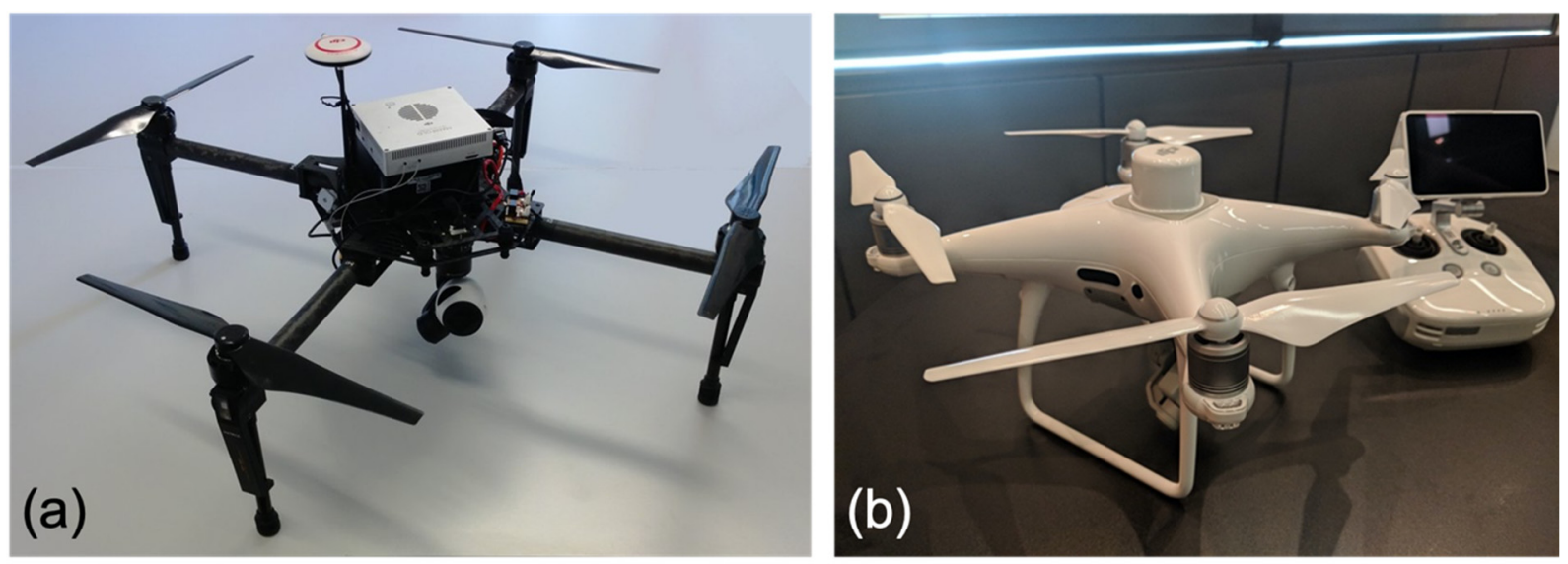

Figure 3. (a) DJI Matrice $100 \mathrm{UAV}$, with the Micasense and RGB Gimbal cameras attached. (b) DJI Phantom 4 RTK UAV.

First released in 2015, the DJI Matrice 100 is a model designed with a customizable aerial platform, ideal for research purposes of attaching small spectral sensors. Including batteries, it weighs $2431 \mathrm{~g}$ with a maximum take-off weight with a payload of $3600 \mathrm{~g}$.

DJI Matrice 100 carried a MicaSense RedEdge (MicaSense Inc., Seattle, WA, USA) [32] narrowband multispectral camera. Multispectral imagery acquisition was aimed to be conducted on fieldwork dates before biomass collection. If the weather for the day was not ideal, flights were scheduled as soon as possible after that to maintain consistency with the plant physiology and field conditions (Table 1). The field flight plan was made in the "Pix4Dcapture" app, part of the Pix4D software suite (Pix4D S.A., Prilly, Switzerland), to cover the whole field in a zigzag pattern (Pix4D Documentation 2020) [33]. Pix4Dcapture has the functions of adding custom UAV and sensor properties to calculate the flight plan's estimated total time, battery usage, and image resolution at selected altitudes. At the study field, wind and gust conditions $>60 \mathrm{~m}$ altitude were often greater than the UAV's manufacturer-recommended limits. Flight altitude was set at $60 \mathrm{~m}$ and based on the MicaSense camera's specifications (image width, sensor width, and focal length) the resulting image resolution was $4 \times 4 \mathrm{~cm}$, suitable for the scale of crop spectral analysis [21]. Image capture was set to $80 \%$ side and $80 \%$ front overlap. To streamline UAV flight patterns and maintain GPS connection with the controller, the study field was divided into two flight plans. Unfortunately, images from one flight on 26 June were corrupted and only data from half of the field were usable. Images taken on and after 2 July could not be mosaicked in Pix4D due to the software limitations with recognizing and stitching the dense crop canopy at middle/later growth stages. Considering the nitrogen estimation for fertilizer management is most important in the early growth stages, data from 2 July onwards were omitted from the rest of this study.

Table 1. Summary of Unmanned Aerial Vehicle (UAV) flight acquisitions with MicaSense RedEdge multispectral camera.

\begin{tabular}{ccc}
\hline Flight Date & Air Temperature $\left({ }^{\circ} \mathbf{C}\right)$ & BBCH $^{*}$ Growth Stage \\
\hline 8 June & 26 & 10 \\
16 June & 25 & 15 \\
26 June & 28 & 31 \\
2 July & 32 & 34 \\
9 July & 33 & 45 \\
15 July & 29 & 53 \\
\hline
\end{tabular}

* Biologische Bundesanstalt, Bundessortenamt und CHemische Industrie Scale [25].

\subsection{UAV Image Processing}

UAV images were processed according to the flowchart of Figure 4. DJI Phantom 4 RTK images, taken in April over the study site's bare soil, were inputted into 
Pix4Dmapper photogrammetry software to generate a continuous 3D point cloud dataset of the field. QGIS, an open-source geographic information software (GIS), was used to convert the point cloud dataset into a DEM in GeoTiff format [34]. The DEM enabled observation of topographic variation within the field, which can affect plant growth related to landscape shape, soil structure, and water flow [6]. Topographic metrics were computed from the DEM with the System for Automated Geoscientific Analysis (SAGA), free, opensource software for spatial data analysis [35]. Topographic metrics exported in GeoTiff format included slope, aspect, profile curvature, plan curvature, and two topographic wetness indices: (TWI) \#1 using a Deterministic 8 algorithm, and TWI \#2 using Multiple Flow Direction algorithm.

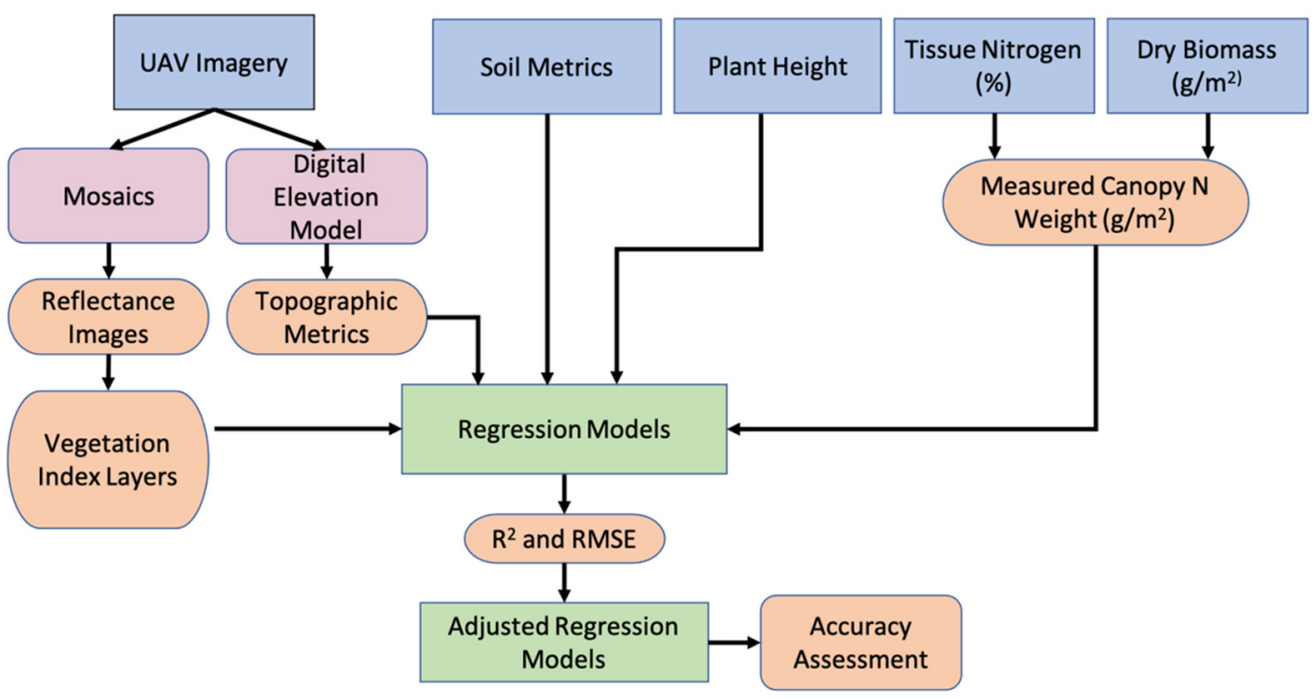

Figure 4. Flowchart of the methodology used in the study.

Multispectral images from the MicaSense camera were processed in Pix4Dmapper to create one orthomosaic image per band. Radiometric calibration of UAV images is important for the quality of image reflectance, taking into consideration the sensor influence and scene illumination. Before each flight, the MicaSense camera was positioned above a MicaSense Calibrated Reflectance Panel to acquire white reference images for each band. In Pix4Dmapper, the sensor settings, properties, and conditions can be obtained from the Exchangeable Image File Format (EXIF) metadata of the images. The white reference images and manufacturer-provided panel reflectance values were inputted in Pix4Dmapper processing options, enabling the software to calibrate and correct images' reflectance for each of the five bands. Pix4Dmapper then uses the Structure from Motion (SfM) algorithm to correct image perspectives to stitch images together [21]. In addition to UAV image geolocation, Pix4Dmapper processing options include georeferencing orthomosaics with ground control points (GCP) to improve the absolute location accuracy. Five GCPs were positioned around the corn field area using black and white checkered boards, with coordinates obtained from a Global Positioning System (GPS) connected with the RTK. The output includes an orthomosaic GeoTiff image file with reflectance values of the entire flight area for each Micasense band.

\subsection{Vegetation Indices}

The orthomosaics for each of the five MicaSense bands were exported into ArcGIS to extract crop canopy reflectance values at the sample points. The MicaSense RedEdge camera bands include the following bands \#: (1) blue, (2) green, (3) red, (4) red-edge, and (5) near-infrared (NIR) (Table 2). 
Table 2. Spectral characteristics of the five Micasense bands.

\begin{tabular}{ccccc}
\hline Band \# & Name & Band Range (nm) & Centre Wavelength (nm) & Bandwidth (nm) \\
\hline 1 & Blue & $465-485$ & 475 & 20 \\
2 & Green & $550-570$ & 560 & 20 \\
3 & Red & $663-673$ & 668 & 10 \\
4 & Red-Edge & $712-722$ & 717 & 10 \\
5 & NIR & $820-860$ & 840 & 40 \\
\hline
\end{tabular}

The orthomosaics were used to compute 11 VIs (Table 3). VIs were already found to be suitable for estimating canopy nitrogen in crops, such as the normalized difference vegetation index (NDVI), green NDVI (GNDVI), and Double-Peak Canopy Nitrogen Index (DCNI) [36]. Some VIs are related to chlorophyll, which was found to be closely related to leaf nitrogen content as the photosynthetic enzyme, rubisco, comprises the largest proportion of nitrogen in leaves [7]. Chlorophyll absorbs more than $70 \%$ of blue and red radiation and reflects green and NIR radiation [37]. The VIs were computed with the Raster calculator function of PCI Geomatica Banff and exported as GeoTiff files. Using ArcGIS, the VI values were extracted at each sample point.

Table 3. Vegetation indices used in the study.

\begin{tabular}{|c|c|c|}
\hline Index $^{1}$ & Formula $^{2}$ & Authors \\
\hline BNDVI & $(\mathrm{NIR}-\mathrm{BLUE}) /(\mathrm{NIR}+\mathrm{BLUE})$ & Wang et al. [38] \\
\hline CI_RE & $(\mathrm{NIR} / \mathrm{REDEDGE})-1$ & Gitelson et al. [39] \\
\hline ISR & RED/NIR & Fernandes et al. [40] \\
\hline MSR & $\frac{(\mathrm{NIR} / \mathrm{RED})-1}{\sqrt{\frac{\mathrm{NIR}}{\mathrm{RED}}+1}}$ & Chen [41] \\
\hline NDVI & $(\mathrm{NIR}-\mathrm{RED}) /(\mathrm{NIR}+\mathrm{RED})$ & Rouse et al. [42] \\
\hline OSAVI & 1.6[(NIR - RED)/(NIR + RED + 0.16)] & Rondeaux, Steven, and Baret [43] \\
\hline NDRE & (NIR - REDEDGE)/(NIR+REDEDGE) & Gitelson and Merzyak [44] \\
\hline RGBVI & $\left(\right.$ GREEN $^{2}-$ BLUE $*$ RED $) /\left(\right.$ GREEN $^{2}+$ BLUE $*$ RED $)$ & Bendig et al. [45] \\
\hline RVI & NIR/RED & Jordan [46] \\
\hline RVI (2) & NIR/REDEDGE & Kanke et al. [47] \\
\hline WDRVI & $(0.2 * \mathrm{NIR}-\mathrm{RED}) /(0.2 * \mathrm{NIR}+\mathrm{RED})$ & Gitelson [48] \\
\hline
\end{tabular}

${ }^{1}$ BNDVI. blue normalized difference vegetation index; CI_RE, chlorophyll index red edge; ISR, infrared simple ratio; MSR, modified simple ratio; NDVI, normalized difference vegetation index; OSAVI, optimized soil adjusted vegetation index; NDRE, normalized difference red edge index; RGBVI, red green blue vegetation index; RVI, ratio vegetation index; WDRVI, wide dynamic range vegetation index. ${ }^{2}$ BLUE, blue reflectance; GREEN, green reflectance; RED, red reflectance; REDEDGE, red edge reflectance; NIR, near-infrared reflectance.

\subsection{Canopy Nitrogen Weight Estimation}

Canopy nitrogen is defined by calculating canopy nitrogen weight using the following method [49]:

$$
\mathrm{CNW}=\left(\mathrm{N}_{\text {plants }} \times \frac{\mathrm{Wd}}{\mathrm{N}_{\text {biomass }}}\right) \times \mathrm{LNC}
$$

where CNW is the canopy nitrogen weight $\left(\mathrm{g} / \mathrm{m}^{2}\right), \mathrm{N}_{\text {plants }}$ is the number of plants in the $1 \mathrm{~m}^{2}$ area over the sampling point, $\mathrm{Wd}$ is the dry biomass weight $\left(\mathrm{g} / \mathrm{m}^{2}\right), \mathrm{N}_{\text {biomass }}$ is the number of plants gathered for biomass at the sampling point, and LNC is the leaf nitrogen content (\%). CNW assumes the plants collected for biomass within a $1 \mathrm{~m}^{2}$ block around the sample point have the same amount of nitrogen. For corn plants, the leaves constitute a majority of dry biomass weight, hence the use of total biomass per area in the formula. Compared to other agronomic parameters, including plant nitrogen concentration (\%), plant nitrate content, and Soil Plant Analysis Development (SPAD) readings, canopy nitrogen weight has been found to have greater correlation with spectral data [50]. 


\subsection{Canopy Nitrogen Weight Modelling}

The modelling approaches in this study include Random Forest (RF) regression and Support Vector Regression (SVR). RF is an ensemble learning method that can be used for classification or regression models of large, nonparametric datasets. The user defines a percentage of the dataset to be randomly selected as training data; $70 \%$ is commonly used. Using the training data, the algorithm generates many decision trees to determine the importance of variables in the regression. Decision trees split at nodes depending on the most contributing independent variable to the dependent variable. The remainder of the dataset not used in training is used as validation data, and the output average of the individual trees is used to evaluate the regression model's performance. Advantages of RF include the algorithm not overfitting from the training data, it is quick to compute, and it has relatively high performance in studies [23].

SVR is part of the Support Vector Machine (SVM) learning algorithm, which uses a decision boundary in a hyperplane to split training data into classes based on the data characteristics. The support vectors that are closest to training samples are used to determine the optimal position of the decision boundary using the midpoint of the margin. SVR performs modelling in a high-dimensional space using the hyperplane. For nonlinear data, SVR uses a kernel trick (i.e., Radial Basis Kernel), which places the data in a dimensional space to separate into groups using the radial distance between data points. Advantages of using SVR include its flexibility with nonparametric data, and it has been found to have better modelling capabilities compared to simple linear regression by capturing nonlinearity [50].

The modelling was written in R programming language using R Studio (Version 4.0.3), a free, open-source Integrated Development Environment (IDE) [51]. RF used the "randomForest" package and SVR used the "e1071" package. For both models, the independent variables were the VIs, Micasense bands, plant physiology variables, topographic metrics, and soil metrics, and the dependent variable was the canopy nitrogen weight. For variable measurements at each sample point, the average of the variable values within a $1 \mathrm{~m}^{2}$ block was used. Data from 8 June, 15 June, and 24 June were randomly divided into $70 \%$ training set and 30\% validation set. Dates were selected based on the availability of the dataset including UAV imagery and in-situ ground measurements. The quality of the models was assessed using the coefficient of determination $\left(R^{2}\right)$ and Root Mean Square Error (RMSE), calculated using Equations (2) and (3), respectively [52]:

$$
R^{2}=1-\frac{\sum\left(y_{i}-\hat{y}_{i}\right)^{2}}{\sum\left(y_{i}-\bar{y}_{i}\right)^{2}}
$$

where $y_{i}$ is the observed value, $\hat{y}_{i}$ is the predicted value, and $\bar{y}$ is the mean of the observed values of the dataset; and:

$$
R M S E=\frac{\sum_{i=1}^{n}\left(\hat{y}_{i}-y_{i}\right)^{2}}{n}
$$

where $\hat{y}_{i}$ is the predicted canopy nitrogen weight value $\left(\mathrm{g} / \mathrm{m}^{2}\right), y_{i}$ is the observed canopy nitrogen weight value $\left(\mathrm{g} / \mathrm{m}^{2}\right), n$ is the number of observations, and $i$ is the index of summation in increments of one.

\section{Results}

\subsection{Nitrogen Statistics}

Canopy nitrogen weight gradually increased in variation from 8 June to 9 July during the early to middle growth stages, then decreased slightly on 15 July (Figure 5). As the crop developed into later growth stages, a decrease in canopy nitrogen results from the dilution effect, as discussed in [53,54]. An outlier is shown in Figure 5, but as it was consistent throughout the growing stages at the same sample point it is unlikely to be due to errors in measurements. 


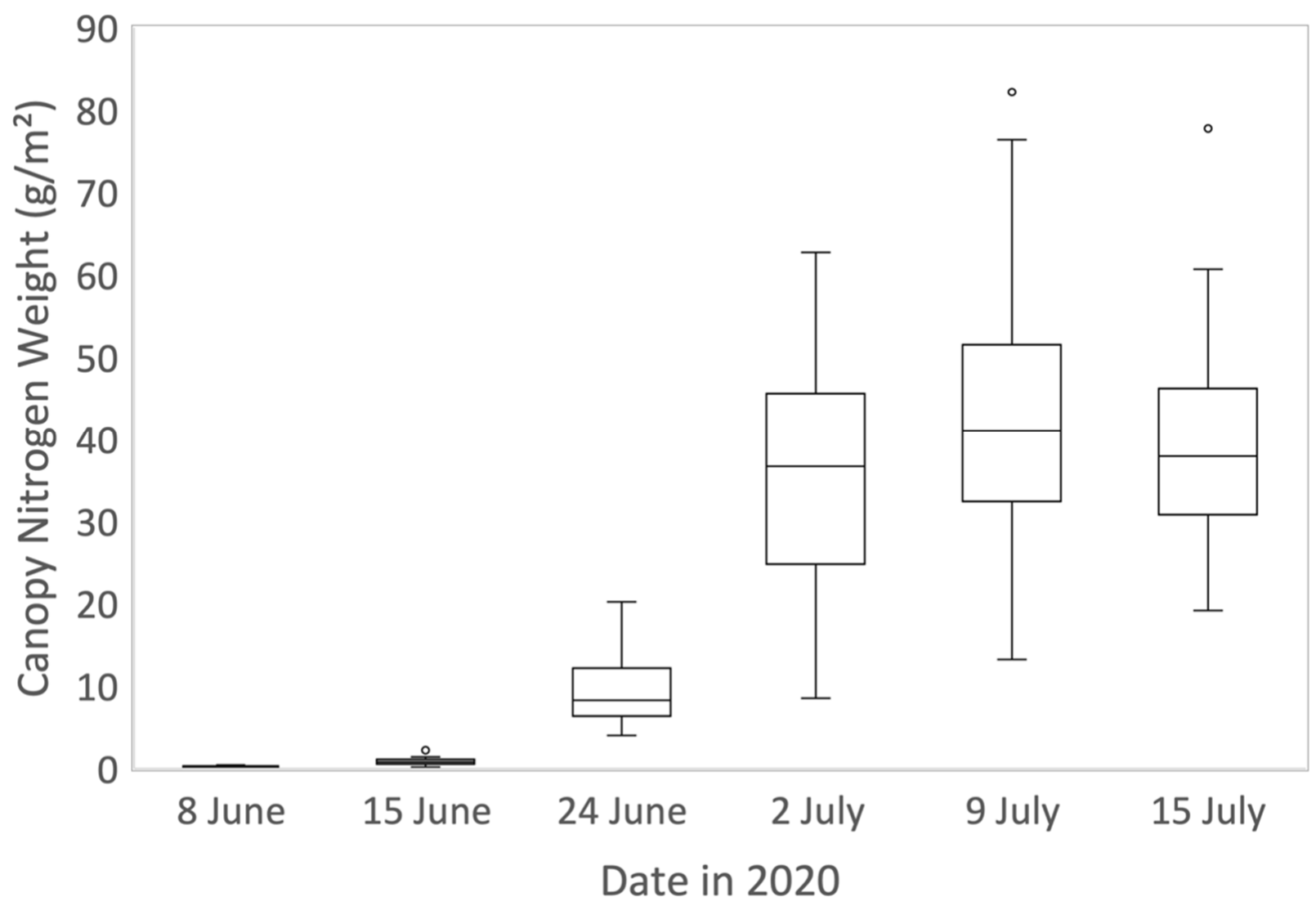

Figure 5. Variation of canopy nitrogen weight $\left(\mathrm{g} / \mathrm{m}^{2}\right)$ as a function of the date of field measurements during the 2020 growing season. Outliers are represented by dots on the graph.

\subsection{Soil Statistics}

The Vittellus soil health analysis [30] produced the following mean values: soil nitratenitrogen of $72.75 \mathrm{ppm}$, mineralizable nitrogen of $30.75 \mathrm{ppm}$, water extracted soil nitrate of $71.38 \mathrm{ppm}$, and water extracted total nitrogen of $88.75 \mathrm{ppm}$. The A\&L's Soil Health Index rating was in the "Good-High" category, and the soil textural class for the field was predominantly silt loam.

\subsection{Regression Models with All Parameters}

First, all 29 parameters including VIs, MicaSense bands, plant physiology variables, soil metrics, and topographic metrics were used in calibrating the RF and SVR model (Table 4). Single date datasets and combinations of the multi-date dataset were tested to evaluate the temporal effect on the models. From all calibrated models, RF had better performance in comparison to SVR. The best performing RF model was obtained with a combination of all three dates, resulting in $R^{2}$ of 0.97 and RMSE of $0.71 \mathrm{~g} / \mathrm{m}^{2}$. Other RF multi-date combinations had high performance close to the best model. Of all the RF models, the lowest $R^{2}$ was at 0.92 with an RMSE of $0.20 \mathrm{~g} / \mathrm{m}^{2}$ for 15 June. For SVR, the 15 June model also had the lowest performance. Although SVR RMSE values were low overall but close to the RMSE of the RF models', single date models of 8 June and 15 June had low $R^{2}$ values at 0.73 and 0.48 respectively. SVR multi-date models had much better performance compared to single-date models, but RMSE values were higher than with the RF multi-date models. 
Table 4. Statistics for the calibration of the canopy nitrogen model with all 29 variables including vegetation indices, the 5 Micasense band reflectances, plant physiology variables, soil metrics, and topographic metrics, as a function of the date and the modeling approach (RF or SVR) ${ }^{1}$.

\begin{tabular}{ccccc}
\hline Date & Model & $\mathbf{R}^{\mathbf{2}}$ & RMSE $\left(\mathbf{g} / \mathbf{m}^{\mathbf{2}}\right)$ & $(\boldsymbol{n})$ \\
\hline 8 June & RF & 0.95 & 0.03 & 28 \\
& SVR & 0.73 & 0.04 & 28 \\
15 June & RF & 0.92 & 0.20 & 28 \\
& SVR & 0.48 & 0.31 & 28 \\
24 June & RF & 0.94 & 1.70 & 14 \\
& SVR & 0.94 & 1.53 & 14 \\
8, 15 June & RF & 0.92 & 0.15 & 56 \\
& SVR & 0.75 & 0.24 & 42 \\
8, 24 June & RF & 0.97 & 0.90 & 42 \\
& SVR & 0.97 & 1.10 & 42 \\
15, 24 June & RF & 0.97 & 0.96 & 42 \\
& SVR & 0.95 & 1.22 & 70 \\
8, 15, 24 June & RF & 0.97 & 0.71 & 1.13 \\
& SVR & 0.96 &
\end{tabular}

${ }^{1}$ All models are significant at $p$-value $<0.001$.

Next, the models were applied to the validation datasets (Table 5). RF with the combination of all three dates performed the best out of the models with $\mathrm{R}^{2}$ of 0.75 and RMSE of $2.29 \mathrm{~g} / \mathrm{m}^{2}$. Compared to the best model, there was only a small difference in the $\mathrm{RF}$ model of 8 June and 24 June with $\mathrm{R}^{2}$ of 0.74 and RMSE of $2.48 \mathrm{~g} / \mathrm{m}^{2}$. Single-date models for both RF and SVR had poor results overall. However, the small number of sample point data in single-date models may have resulted in the calibration model not encompassing normal variation in the field data. Overall, multi-date models had better performance compared to single-date models.

Table 5. Statistics for the validation of the canopy nitrogen model with all 29 variables including selected vegetation indices, the 5 Micasense bands, plant physiology variables, soil metrics, and topographic metrics as a function of the date and modelling approach (RF or SVR).

\begin{tabular}{cccccc}
\hline Date & Model & $\mathbf{R}^{\mathbf{2}}$ & $\boldsymbol{p}$-Value & RMSE $\left(\mathbf{g} / \mathbf{m}^{\mathbf{2}}\right)$ & $(\boldsymbol{n})$ \\
\hline 8 June & RF & 0.14 & NS & 0.09 & 12 \\
& SVR & 0.23 & 0.100 & 0.08 & 12 \\
15 June & RF & 0.04 & NS & 0.40 & 12 \\
& SVR & 0.01 & NS & 0.39 & 12 \\
24 June & RF & 0.30 & NS & 4.07 & 6 \\
& SVR & 0.02 & NS & 3.37 & 6 \\
8, 15 June & RF & 0.50 & $<0.001$ & 0.31 & 24 \\
& SVR & 0.36 & 0.001 & 0.34 & 24 \\
8, 24 June & RF & 0.74 & $<0.001$ & 2.48 & 18 \\
& SVR & 0.69 & $<0.001$ & 2.28 & 18 \\
15, 24 June & RF & 0.63 & $<0.001$ & 3.13 & 18 \\
& SVR & 0.53 & $<0.001$ & 2.85 & 18 \\
8, 15, 24 June & RF & 0.75 & $<0.001$ & 2.29 & 30 \\
& SVR & 0.58 & $<0.001$ & 2.21 & 30 \\
\hline
\end{tabular}

${ }^{1} \mathrm{NS}=$ non-significant.

\subsection{Variable Importance Plot}

RF modelling can be visualized with a variable importance plot in $\mathrm{R}$ Studio using the "varImpPlot()" function (Figure 6). The more important an explanatory variable is in the prediction of canopy nitrogen weight, the higher its IncNodePurity value is. Using the dataset containing all dates and the 29 variables used in the model, plant height was the most important predictor. The top ten variables were made by 7 from the 11 VIs used and 2 MicaSense band reflectance mosaics (blue and red). Among all the topographic metrics, 
the profile curvature was the top-performing variable. From the soil metrics, soil moisture was the top-performing variable.

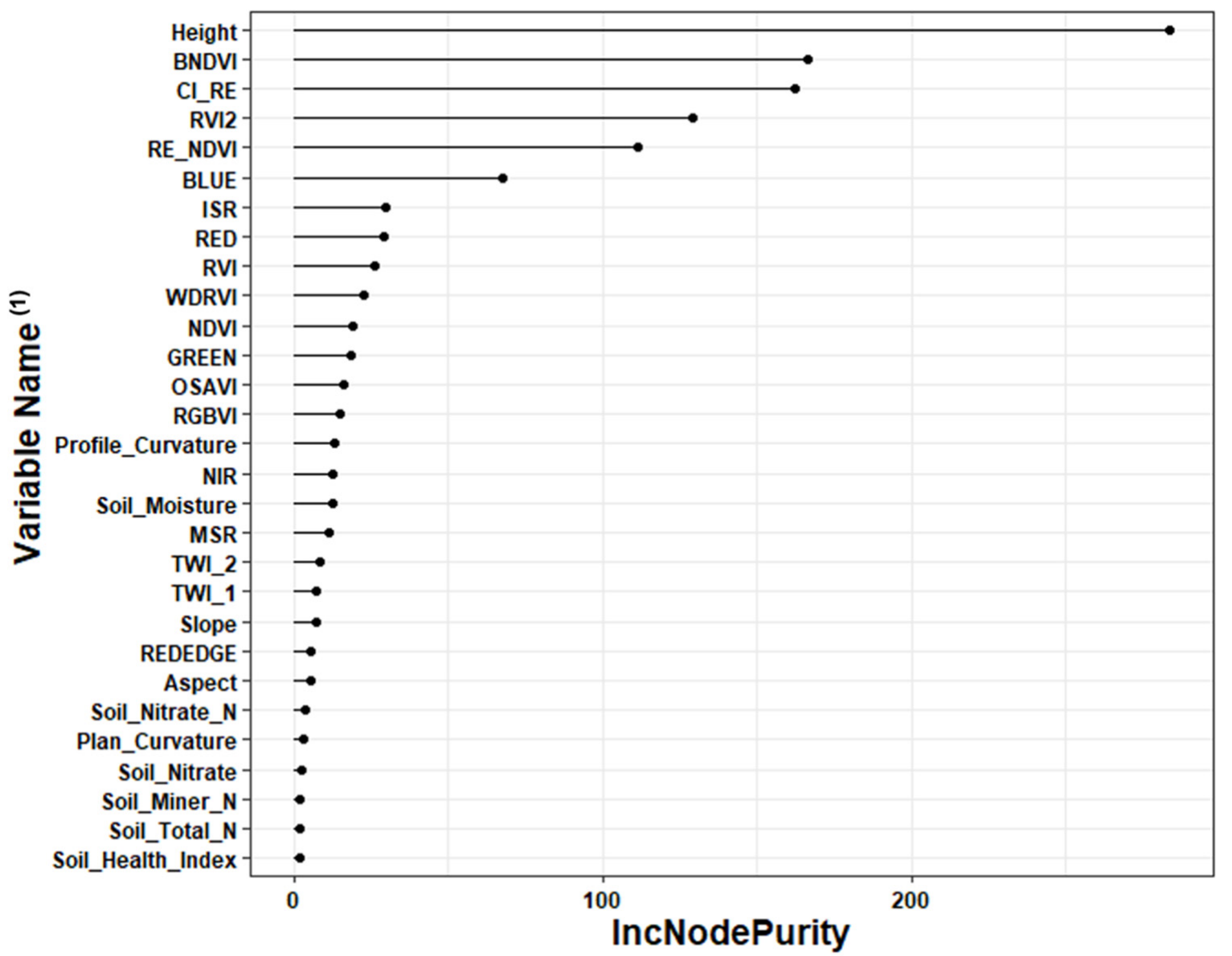

Figure 6. Variance Importance plot produced by the Random Forest model of all three dates and 30 variables, using the function varImpPlot() in R Studio. Higher IncNodePurity values indicate more impact on nitrogen. ${ }^{(1)}$ Please refer to Table 1 for the full name of vegetation indices. N_Weight, plant nitrogen weight; Soil_Nitrate_N, soil nitrate nitrogen (NO3-N); Soil_Miner_N, soil mineralizable nitrogen; Soil_Total_N, water extracted total soil nitrogen; TWI_1, total wetness index \#1; TWI_2, total wetness index \#2.

\subsection{Regression Models with Selected Variables}

As the best performing model from the calibration and validation datasets was the combination of all three dates using RF, we tested numerous variable combinations with the data from all three dates. Based on Figure 6, we selected the top 6, 10, 15, 18, and 20 variables based on the evaluation of variable importance thresholds. In addition, we considered a separate group containing all spectral variables, because all the VIs and MicaSense band reflectance mosaics, except the red-edge band mosaic, were in the top 20 variables. Table 6 displays the statistics of RF and SVR applied to the various combinations of variables from calibration datasets. Overall, RF had better performance than SVR, but there was not a large difference in the $\mathrm{R}^{2}$ or RMSE values. The best model was RF with the combination of top 20 variables, resulting in a $\mathrm{R}^{2}$ value of 0.97 and a RMSE of $0.70 \mathrm{~g} / \mathrm{m}^{2}$. However, in comparison to the best model, there were only small differences in $\mathrm{R}^{2}$ and RMSE for the RF models. 
Table 6. Statistics for the calibration of the canopy nitrogen model with all dates (8, 15, and 24 June), and different combinations of variables $(n=70)^{1}$.

\begin{tabular}{|c|c|c|c|c|}
\hline Input Variables & Model & Number of Variables & $R^{2}$ & $\operatorname{RMSE}\left(\mathrm{g} / \mathrm{m}^{2}\right)$ \\
\hline \multirow{2}{*}{ All VIs \& 5 MicaSense bands } & RF & 13 & 0.95 & 0.93 \\
\hline & SVR & 13 & 0.88 & 1.50 \\
\hline \multirow{2}{*}{ Top 6: Height, BNDVI, CI_RE, RVI2, RE_NDVI, BLUE } & RF & 6 & 0.97 & 0.73 \\
\hline & SVR & 6 & 0.95 & 1.01 \\
\hline \multirow{2}{*}{ Top 10: Top 6 + ISR, RED, RVI, WDRVI } & RF & 10 & 0.96 & 0.81 \\
\hline & SVR & 10 & 0.95 & 1.06 \\
\hline \multirow{2}{*}{ Top 15: Top 10 + NDVI, GREEN, OSAVI, RGBVI, Profile Curvature } & RF & 15 & 0.97 & 0.74 \\
\hline & SVR & 15 & 0.96 & 0.96 \\
\hline \multirow{2}{*}{ Top 18: Top 15 + NIR, Soil Moisture, MSR } & RF & 18 & 0.97 & 0.73 \\
\hline & SVR & 18 & 0.95 & 1.05 \\
\hline \multirow{2}{*}{ Top 20: Top 18 + TWI_2, TWI 1} & RF & 20 & 0.97 & 0.70 \\
\hline & SVR & 20 & 0.95 & 1.10 \\
\hline
\end{tabular}

${ }^{1}$ All models are significant at $p$-value $<0.001$.

The models were then applied to the validation datasets (Table 7). The RF model using the top 15 variables had the best performance with an $\mathrm{R}^{2}$ value of 0.73 and an RMSE of $2.21 \mathrm{~g} / \mathrm{m}^{2}$. Compared to the top-performing model, the RF model using the top 18 variables had the same $\mathrm{R}^{2}$ value with a slightly higher RMSE. Of the top 15 variables, only the plant height and the profile curvature were non-spectral variables. All RF models had higher $\mathrm{R}^{2}$ values than SVM, but the RF model has RMSE values that were slightly higher as well. The RF variable importance plot allows identification of the variables that do not affect the model significantly. As found in the models with the top 20 variables, removing low importance variables from a model can improve the results.

Table 7. Statistics for the validation of the canopy nitrogen model with all dates (8, 15, and 24 June), and different combinations of variables $(n=30)^{1}$.

\begin{tabular}{|c|c|c|c|c|}
\hline Input Variables & Model & Number of Variables & $R^{2}$ & $\operatorname{RMSE}\left(\mathrm{g} / \mathrm{m}^{2}\right)$ \\
\hline \multirow{2}{*}{ All VIs \& 5 MicaSense bands } & RF & 13 & 0.61 & 2.89 \\
\hline & SVR & 13 & 0.58 & 2.31 \\
\hline \multirow{2}{*}{ Top 6: Height, BNDVI, CI_RE, RVI2, RE_NDVI, BLUE } & RF & 6 & 0.67 & 2.50 \\
\hline & SVR & 6 & 0.67 & 2.16 \\
\hline \multirow{2}{*}{ Top 10: Top 6 + ISR, RED, RVI, WDRVI } & RF & 10 & 0.68 & 2.47 \\
\hline & SVR & 10 & 0.66 & 2.06 \\
\hline \multirow{2}{*}{ Top 15: Top 10 + NDVI, GREEN, OSAVI, RGBVI, Profile Curvature } & RF & 15 & 0.73 & 2.21 \\
\hline & SVR & 15 & 0.60 & 2.23 \\
\hline \multirow{2}{*}{ Top 18: Top 15 + NIR, Soil Moisture, MSR } & RF & 18 & 0.73 & 2.25 \\
\hline & SVR & 18 & 0.67 & 1.97 \\
\hline \multirow{2}{*}{ Top 20: Top 18 + TWI_2, TWI 1} & RF & 20 & 0.71 & 2.36 \\
\hline & SVR & 20 & 0.59 & 2.17 \\
\hline
\end{tabular}

${ }^{1}$ All models are significant at $p$-value $<0.001$.

\section{Discussion}

In this study, RF and SVM regression methods were used to predict canopy nitrogen weight of corn using UAV Micasense individual band reflectance, associated VIs, plant physiology variables, topographic metrics, and soil metrics. The variation of the in-situ canopy nitrogen weight measurements was very low in the earliest growth stage on 8 June and gradually increased until the latest sampling date of 15 July, with a marked decrease afterwards. The increase in canopy nitrogen variation during the early growth 
stages of $\mathrm{BBCH}$ 00-49 can be explained by the leaf growth and stem elongation because the crop biomass increases rapidly during that period. Then, as the plant reaches the $\mathrm{BBCH}$ 51 stage that corresponds to the inflorescence emergence and heading, the canopy nitrogen variation decreases because of the dilution effect [6].

The RF and SVR models were first calibrated with all the 29 variables using single and multi-date datasets. With the validation datasets, single-date models had overall poor performance. Combinations of multi-date models led to better results, with the best performance obtained with the RF model. In the variance importance plot of the best RF model, the plant height was the most important predictor out of all variables used. Freeman et al. [55] already found that plant height is a useful variable in identifying nitrogen uptake in corn. Precision agriculture studies have used crop height for phenology, biomass, and yield prediction successfully, and this crop height can be derived from UAV point cloud datasets [56]. Among all the individual MicaSense band reflectances, the reflectance of the red-edge band has the poorest performance. The red-edge region (680-800 nm) represents a sharp change in the canopy reflectance and can provide important details about phenology [47]. Our result agrees with Lee et al.'s [23] work that uses the same Micasense camera. Likely, the narrow $10 \mathrm{~mm}$ band range of the red-edge band of the Micasense camera did not capture the change in the region well. This could explain why our results are not in agreement with several other studies that find that the red-edge region is a sensitive indicator of leaf chlorophyll content, because of the high absorption in the red radiation and the high reflectance in the near-infrared region during plant growth stages [57,58]. Overall, most of the soil metrics had little to no effect on the models, but the soil was sampled once at the beginning of the growing season. With the consideration of costs and historical farm operations where recommendations for soil tests are only once a year, this study emphasizes the limitations of the current soil testing practices. Soil metrics results from Mulvaney et al.'s [59] and Tremblay et al.'s [60] studies on a soil-based approach in corn nitrogen management, found that soil tests were useful in their models when field conditions were conducive to soil nitrogen mineralization, crop uptake, and utilization. With different sampling methods, soil metrics may still be useful in models. There is therefore the need to conduct soil tests at different dates to better characterize the soil condition changes, for example, because of fertilizer applications, precipitation patterns, and crop growth [7].

The RF model's variable importance plot allowed selecting groups of top 6, 10, 15, 18, and 20 variables for developing new RF and SVM models. The top 20 variables included plant height, all the 11 VIs used in this study, all the MicaSense band reflectance mosaic but the red-edge one, the soil moisture, and the profile curvature, as well as the topographic wetness indices \#1 and \#2. The group of top 15 variables that performed best has only the plant height and profile curvature as non-spectral parameters. Considering that topographic metrics were derived from the UAV Phantom 4 RTK imagery along with the possibility of deriving crop height across the field from point cloud data, all variables in the best model can be measured from in-situ, non-destructive, UAV-based data collection [55]. Having all model data that can be collected by remote sensing could be a greater benefit, as common limitations of in-situ studies and subsequent application methods are the intensive labour and high costs required to obtain model input data.

In this study, the final validation of canopy nitrogen models with various combinations of variables indicated RF models had better performance than SVR in terms of $\mathrm{R}^{2}$ values. This is consistent with results from Liu et al. [61], Zha et al. [62], and Lee et al. [23], with RF yielding better nitrogen content prediction in wheat, rice, and corn crops compared to SVR models. Although SVR had lower RMSE values in comparison to RF, overall RF RMSE values were low as well in the context of nitrogen estimation for $\mathrm{g} / \mathrm{m}^{2}$. In comparison to the study by Lee et al. [23], the RMSE values of this study's models are much lower, which can be beneficial for fertilizer management recommendations to farmers in general. In the case of this study, the RF algorithmic method of using many decision trees may better suit the use of numerous variables in regression models. In comparison, using many 
variables in SVR requires user hyper-tuning and the kernel trick function to separate data into groups, relying on the radial distance between points to be meaningful in the model. Overall, the performance of SVR models was good, but RF models can be considered more useful in terms of ease of use and the quality of results.

\section{Conclusions}

This study tested machine learning regression methods to predict corn canopy nitrogen weight using UAV Micasense band reflectance mosaics, associated VIs, plant physiology variables, topographic metrics, and soil metrics. With all 29 variables in RF and SVR models, the combination of all three dates with the RF model produced the best results: The validation model having an $\mathrm{R}^{2}$ of 0.75 and an RMSE of $2.29 \mathrm{~g} / \mathrm{m}^{2}$. From the multi-date RF model's variable importance plot, the top $6,10,15,18$, and 20 variables were tested in RF and SVR models. The best validation model was the RF model $\left(R^{2}\right.$ value at 0.73 and RMSE at $2.21 \mathrm{~g} / \mathrm{m}^{2}$ ) with the top 15 variables, most of them being spectral variables.

We developed models for estimating canopy nitrogen weight from spectral, plant, soil, and topographic variables using machine learning algorithms, but the resulting models are still empirical, and their applicability can be limited to the dataset on which they were built and validated. This is a common limitation in agricultural research as in-situ measurements often require intensive labour, costs, and variable conditions. Overall, many factors need to be considered to define plant growth conditions such as plant species, soil condition, environmental factors of field topology, moisture supply, weather, and more. There is a need to test the developed models on other datasets to determine their efficacy and to understand their applicability in precision agriculture. Future work can consider using a more deterministic modelling approach, for example, the PROSAIL model [63], as it is less empirical and applies to a high variety of conditions but requires more advanced parameter calibration. The PROSAIL model uses spectral data of leaf and canopy level parameters to retrieve chlorophyll and nitrogen content, with robust results from lab and field studies [63]. Eventually, methods of crop height extraction from RTK UAVs [56], in addition to UAV-derived topographic and spectral variables, can be used to develop a final map for a whole field. The model information can be used to improve field nitrogen prediction, leading to more effective and efficient $\mathrm{N}$ fertilizer management.

Author Contributions: Conceptualization, J.Y., J.W. and B.L.; methodology, J.Y., J.W. and B.L.; software, J.Y.; validation, J.W. and B.L.; formal analysis, J.Y.; investigation, J.Y.; resources, J.W. and B.L.; data curation, J.Y.; writing—original draft preparation, J.Y.; writing—review and editing, J.Y., J.W. and B.L.; visualization, J.Y.; supervision, J.W. and B.L.; project administration, B.L.; funding acquisition, B.L. and J.W. All authors have read and agreed to the published version of the manuscript.

Funding: This research is funded by the NSERC CRD grant number CRDPJ507141-16, awarded to Leblon and Wang, and is the result of a collaboration between the University of New Brunswick, University of Western Ontario, and A\&L Canada Laboratories Inc. Additional funding is provided by the NSERC discovery grant awarded to Wang and Ontario graduate Scholarship awarded to Yu.

Institutional Review Board Statement: Not applicable.

Informed Consent Statement: Not applicable.

Data Availability Statement: The data collected for this paper are not publicly available.

Acknowledgments: The authors thank A\&L Canada Laboratories Inc. staff and Wang's GITA lab members for their assistance with data collection, lab processing, and support. Special thanks go to Hwang Lee, Marco Chiu, Robin Kwik, Bo Shan, Yang Song, Chunhua Liao, and Naythan Samuda for their assistance in fieldwork and guidance. The authors would also like to thank the anonymous reviewers for their helpful comments and feedbacks for this manuscript.

Conflicts of Interest: The authors declare no conflict of interest. 


\section{References}

1. Tan, C.S.; Reynolds, W.D. Impacts of recent climate trends on agriculture in southwestern Ontario. Can. Water Resour. 2003, 28, 87-97. [CrossRef]

2. Bongiovanni, R.; Lowenberg-Deboer, J. Precision agriculture and sustainability. Precis. Agric. 2004, 5, 359-387. [CrossRef]

3. Masclaux-Daubresse, C.; Daniel-Vedele, F.; Dechorgnat, J.; Chardon, F.; Gaufichon, L.; Suzuki, A. Nitrogen uptake, assimilation and remobilization in plants: Challenges for sustainable and productive agriculture. Ann. Bot. 2010, 105, 1141-1157. [CrossRef]

4. Sishodia, R.P.; Ray, R.L.; Singh, S.K. Applications of remote sensing in precision agriculture: A review. Remote Sens. 2020, $12,3136$. [CrossRef]

5. Good, A.G.; Shrawat, A.K.; Muench, D.G. Can less yield more? Is reducing nutrient input into the environment compatible with maintaining crop production? Trends Plant Sci. 2004, 9, 597-605. [CrossRef]

6. Fageria, N.K.; Baligar, V.C.; Jones, C.A. Growth and Mineral Nutrition of Field Crops, 3rd ed.; CRC Press: New York, NY, USA, 2010.

7. Marschner, H. Marschner's Mineral Nutrition of Higher Plants, 2nd ed.; Academic Press: Cambridge, MA, USA, 2011.

8. Fageria, N.K. The Use of Nutrients in Crop Plants; CRC Press: New York, NY, USA, 2009.

9. Bryant, C.R.; Smit, B.; Brklacich, M.; Johnston, T.R.; Smithers, J.; Chiotti, Q.; Singh, B. Adaptation in Canadian agriculture to climatic variability and change. In Societal Adaptation to Climate Variability and Change; Kane, S., Yohe, G., Eds.; Springer: Dordrecht, Germany, 2000; Volume 1, pp. 181-201.

10. Wolfe, A.H.; Patz, J.A. Reactive nitrogen and human health: Acute and long-term implications. AMBIO J. Hum. Environ. 2002, 31, 120-125. [CrossRef] [PubMed]

11. Food and Agriculture Organization of the United Nations. Adaptation to Climate Change in Agriculture, Forestry and Fisheries: Perspective, Framework, and Priorities; Food and Agriculture Organization of the United Nations: Rome, Italy, 2007. Available online: www.fao.org/nr/climpag/pub/adaptation_to_climate_change_2007.pdf (accessed on 2 April 2021).

12. Lee, H.; Wang, J.; Leblon, B. Intra-field canopy nitrogen retrieval from unmanned aerial vehicle imagery for wheat and corn fields. Can. J. Remote Sens. 2020, 46, 454-472. [CrossRef]

13. Zhu, Y.; Yao, X.; Tian, Y.; Liu, X.; Cao, W. Analysis of common canopy vegetation indices for indicating leaf nitrogen accumulations in wheat and rice. Int. J. Appl. Earth Obs. Geoinf. 2008, 10, 1-10. [CrossRef]

14. Eitel, J.U.H.; Long, D.S.; Gessler, P.E.; Smith, A.M.S. Using in-situ measurements to evaluate the new RapidEye satellite series for prediction of wheat nitrogen status. Int. J. Remote Sens. 2007, 28, 4183-4190. [CrossRef]

15. Sripada, R.P.; Schmidt, J.P.; Dellinger, A.E.; Beegle, D.B. Evaluating multiple indices from a canopy reflectance sensor to estimate corn n requirements. Agron. J. 2008, 100, 1553-1561. [CrossRef]

16. Frels, K.; Guttieri, M.; Joyce, B.; Leavitt, B.; Baenziger, P.S. Evaluating canopy spectral reflectance vegetation indices to estimate nitrogen use traits in hard winter wheat. Field Crop. Res. 2018, 217, 82-92. [CrossRef]

17. Agriculture and Agri-Food Canada. An Overview of the Canadian Agriculture and Agri-Food System; Agriculture and Agri-Food Canada: Ottawa, ON, Canada, 2007. Available online: www.agr.gc.ca/eng/canadas-agriculture-sectors/an-overview-of-thecanadian-agriculture-and-agri-food-system-2017/?id=1510326669269 (accessed on 23 February 2021).

18. U.S. Geological Survey. Landsat Satellite Missions; U.S. Geological Survey: Reston, VA, USA, 2021. Available online: www.usgs.gov / core-science-systems / nli/landsat/landsat-satellite-missions?qt-science_support_page_related_con=0\#qtscience_support_page_related_con (accessed on 10 April 2021).

19. European Space Agency. Sentinel-2; European Space Agency: Paris, France, 2020. Available online: sentinel.esa.int/web/sentinel/ missions/sentinel-2 (accessed on 25 April 2021).

20. Mulla, D.J. Twenty five years of remote sensing in precision agriculture: Key advances and remaining knowledge gaps. Biosyst. Eng. 2013, 114, 358-371. [CrossRef]

21. Harwin, S.; Lucieer, A. Assessing the accuracy of georeferenced point clouds produced via multi-view stereopsis from unmanned aerial vehicle (UAV) imagery. Remote Sens. 2012, 4, 1573-1599. [CrossRef]

22. Hunt, J.E.R.; Hively, W.D.; Fujikawa, S.J.; Linden, D.S.; Daughtry, C.S.T.; McCarty, G.W. Acquisition of NIR-green-blue digital photographs from unmanned aircraft for crop monitoring. Remote Sens. 2010, 2, 290-305. [CrossRef]

23. Lee, H.; Wang, J.; Leblon, B. Using linear regression, random forests, and support vector machine with unmanned aerial vehicle multispectral images to predict canopy Nitrogen weight in corn. Remote Sens. 2020, 12, 2071. [CrossRef]

24. Chen, P.; Haboudane, D.; Tremblay, N.; Wang, J.; Vigneault, P.; Li, B. New spectral indicator assessing the efficiency of crop nitrogen treatment in corn and wheat. Remote Sens. Environ. 2010, 114, 1987-1997. [CrossRef]

25. Meier, U. Growth Stages of Mono- and Dicotyledonous Plants; Blackwell: Berlin, Germany, 1997; (digitalised 2018).

26. Hansen, N.C.; Tubbs, S.; Fernandez, F.; Green, S.; Hansen, N.E.; Stevens, W.B. Conservation agriculture in North America. In Conservation Agriculture; Springer: Cham, Germany, 2015; Volume 1, pp. 417-441. [CrossRef]

27. Vetsch, J.A.; Randall, G.W. Corn production as affected by nitrogen application timing and tillage. Agron. J. 2004, 96, 502-509. [CrossRef]

28. AOAC. Microchemical determination of carbon, hydrogen, and nitrogen, automated method. In Official Methods of Analysis, 18th ed.; Association of Official Analytical Chemists: Gaithersburgs, MD, USA, 2006; pp. 5-6.

29. Delta-T Devices Ltd. User Manual for the ML3 ThetaProbe; Delta-T Devices Ltd.: Cambridge, UK, 2017. Available online: delta-t.co.uk/wp-content/uploads/2017/02/ML3-user-manual-version-2.1.pdf (accessed on 3 May 2020). 
30. A\&L Canada Laboratories. VitTellus Soil Health Test \& VitTellus Bio. Available online: www.alcanada.com/content/solutions/ soil-health (accessed on 14 June 2020).

31. Da-Jiang Innovations. DJI. Available online: www.dji.com/ca (accessed on 15 April 2021).

32. MicaSense. MicaSense-An Ageagle Company. Available online: micasense.com/about/ (accessed on 15 April 2021).

33. Pix4D. How to Improve the Outputs of Dense Vegetation Areas; Pix4D: Prilly, Switzerland, 2020. Available online: support.pix4d.com/ hc/en-us/articles/202560159-How-to-improve-the-outputs-of-dense-vegetation-areas (accessed on 2 March 2021).

34. QGIS 3.16. Geographic Information System Developers Manual. 2021. Available online: docs.qgis.org/3.16/en/docs/developers_ guide/index.html (accessed on 25 February 2021).

35. Conrad, O.; Bechtel, B.; Bock, M.; Dietrich, H.; Fischer, E.; Gerlitz, L.; Wehberg, J.; Wichmann, V.; Böhner, J. System for automated geoscientific analyses (SAGA) v. 2.1.4. Geosci. Model Dev. 2015, 8, 1991-2007. [CrossRef]

36. Jones, H.G.; Vaughan, R.A. Remote Sensing of Vegetation: Principles, Techniques, and Applications, 1st ed.; University Press: New York, NY, USA, 2010.

37. Daughtry, C.S.T.; Walthall, C.L.; Kim, M.S.; de Colstoun, E.B.; McMurtrey, J.E. Estimating corn leaf chlorophyll concentration from leaf and canopy reflectance. Remote Sens. Environ. 2000, 74, 229-239. [CrossRef]

38. Wang, F.-M.; Huang, J.-F.; Tang, Y.-L.; Wang, X.-Z. New vegetation index and its application in estimating leaf area index of Rice. Rice Sci. 2007, 14, 195-203. [CrossRef]

39. Gitelson, A.A.; †, Y.G.; Merzlyak, M.N. Relationships between leaf chlorophyll content and spectral reflectance and algorithms for non-destructive chlorophyll assessment in higher plant leaves. J. Plant Physiol. 2003, 160, 271-282. [CrossRef]

40. Fernandes, R.; Butson, C.; Leblanc, S.; Latifovic, R. Landsat-5 TM and Landsat-7 ETM+ based accuracy assessment of leaf area index products for Canada derived from SPOT-4 vegetation data. Can. J. Remote Sens. 2003, 29, 241-258. [CrossRef]

41. Chen, J.M. Evaluation of Vegetation Indices and a Modified Simple Ratio for Boreal Applications. Can. J. Remote Sens. 1996, 22, 229-242. [CrossRef]

42. Rouse, J.W.; Haas, R.H.; Schell, J.A.; Deering, D.W. Monitoring vegetation systems in the Great Plains with ERTS. NASA Spec. Publ. 1974, 351, 309.

43. Rondeaux, G.; Steven, M.; Baret, F. Optimization of soil-adjusted vegetation indices. Remote Sens. Environ. 1996, 55, 95-107. [CrossRef]

44. Gitelson, A.; Merzlyak, M.N. Quantitative estimation of chlorophyll-a using reflectance spectra: Experiments with autumn chestnut and maple leaves. J. Photochem. Photobiol. B Biol. 1994, 22, 247-252. [CrossRef]

45. Bendig, J.; Yu, K.; Aasen, H.; Bolten, A.; Bennertz, S.; Broscheit, J.; Gnyp, M.L.; Bareth, G. Combining UAV-based plant height from crop surface models, visible, and near infrared vegetation indices for biomass monitoring in barley. Int. J. Appl. Earth Obs. Geoinf. 2015, 39, 79-87. [CrossRef]

46. Jordan, C.F. Derivation of leaf-area index from quality of light on the forest floor. Ecology 1969, 50, 663-666. [CrossRef]

47. Kanke, Y.; Raun, W.; Solie, J.; Stone, M.; Taylor, R. Red edge as a potential index for detecting differences in plant nitrogen status in winter wheat. J. Plant Nutr. 2012, 35, 1526-1541. [CrossRef]

48. Gitelson, A.A. Remote estimation of crop fractional vegetation cover: The use of noise equivalent as an indicator of performance of vegetation indices. Int. J. Remote Sens. 2013, 34, 6054-6066. [CrossRef]

49. Hansen, P.; Schjoerring, J. Reflectance measurement of canopy biomass and nitrogen status in wheat crops using normalized difference vegetation indices and partial least squares regression. Remote Sens. Environ. 2003, 86, 542-553. [CrossRef]

50. James, G.; Witten, D.; Hastie, T.; Tibshirani, R. An Introduction to Statistical Learning: With Applications in R; Springer: New York, NY, USA, 2013.

51. RStudio Team. RStudio: Integrated Development for R; RStudio: Boston, MA, USA, 2020; Available online: www.rstudio.com/ (accessed on 2 March 2021).

52. Palaniswamy, U. Handbook of Statistics for Teaching and Research in Plant and Crop Science; The Haworth Reference Press: New York, NY, USA, 2006.

53. Justes, E.; Mary, B.; Meynard, J.M.; Machet, J.M.; Thelier-Huché, L. Determination of a critical nitrogen dilution curve for winter wheat crops. Ann. Bot. 1994, 74, 397-407. [CrossRef]

54. Li, F.; Gnyp, M.L.; Jia, L.; Miao, Y.; Yu, Z.; Koppe, W.; Bareth, G.; Chen, X.; Zhang, F. Estimating N status of winter wheat using a handheld spectrometer in the North China Plain. Field Crop. Res. 2008, 106, 77-85. [CrossRef]

55. Freeman, K.W.; Girma, K.; Arnall, D.B.; Mullen, R.W.; Martin, K.L.; Teal, R.K.; Raun, W.R. By-plant prediction of corn forage biomass and nitrogen uptake at various growth stages using remote sensing and plant height. Agron. J. 2007, 99, 530-536. [CrossRef]

56. Song, Y.; Wang, J. Winter wheat canopy height extraction from UAV-based point cloud data with a moving cuboid filter. Remote Sens. 2019, 11, 1239. [CrossRef]

57. Schlemmer, M.; Gitelson, A.; Schepers, J.; Ferguson, R.; Peng, Y.; Shanahan, J.; Rundquist, D. Remote estimation of nitrogen and chlorophyll contents in maize at leaf and canopy levels. Int. J. Appl. Earth Obs. Geoinf. 2013, 25, 47-54. [CrossRef]

58. Gahrouei, O.R.; McNairn, H.; Hosseini, M.; Homayouni, S. Estimation of crop biomass and leaf area index from multitemporal and multispectral imagery using machine learning approaches. Can. J. Remote Sens. 2020, 46, 84-99. [CrossRef]

59. Mulvaney, R.L.; Khan, S.A.; Ellsworth, T.R. Need for a soil-based approach in managing nitrogen fertilizers for profitable corn production. Soil Sci. Soc. Am. J. 2006, 70, 172-182. [CrossRef] 
60. Tremblay, N.; Bouroubi, Y.M.; Bélec, C.; Mullen, R.W.; Kitchen, N.R.; Thomason, W.E.; Ebelhar, S.; Mengel, D.B.; Raun, W.; Francis, D.D.; et al. Corn response to nitrogen is influenced by soil texture and weather. Agron. J. 2012, 104, 1658-1671. [CrossRef]

61. Liu, Y.; Cheng, T.; Zhu, Y.; Tian, Y.; Cao, W.; Yao, X.; Wang, N. Comparative analysis of vegetation indices, non-parametric and physical retrieval methods for monitoring nitrogen in wheat using UAV-based multispectral imagery. In Proceedings of the IEEE International Geoscience and Remote Sensing Symposium (IGARSS), Beijing, China, 10-15 July 2016.

62. Zha, H.; Miao, Y.; Wang, T.; Li, Y.; Zhang, J.; Sun, W.; Feng, Z.; Kusnierek, K. Improving unmanned aerial vehicle remote sensing-based rice nitrogen nutrition index prediction with machine learning. Remote Sens. 2020, 12, 215. [CrossRef]

63. Jay, S.; Maupas, F.; Bendoula, R.; Gorretta, N. Retrieving LAI, chlorophyll and nitrogen contents in sugar beet crops from multi-angular optical remote sensing: Comparison of vegetation indices and PROSAIL inversion for field phenotyping. Field Crop. Res. 2017, 210, 33-46. [CrossRef] 